\title{
New developments in the pathology of malignant lymphoma. A review of the literature published from June-August 2014
}

\author{
J. Han van Krieken
}

Published online: 7 September 2014

(C) Springer-Verlag Berlin Heidelberg 2014

\section{Introduction}

Developments in the knowledge on lymphoma remain interesting but it is becoming increasingly difficult to select the most appropriate new information. For this series of reviews, I excluded case reports and reviews. However, I do recognize the importance of both modalities for communication. My selection is based on what I feel are relevant articles that may help the hematopathologists to better understand what he or she sees through the microscope or that enables improved service to patients. But of course, this is highly subjective, and thus, there is some overrepresentation of topics that I have worked on as well as topics that are new to me.

\section{Biology of lymphoma}

B cell lymphomas

Gastric extranodal marginal zone B cell lymphoma (ENMZL) is an example of a disease I have strong interest in. The appealing concept of its development as constructed by Peter Isaacson sets lymphoma development in the setting of an immune response. Michaeli et al. [1] investigated the composition of the immunoglobulin gene repertoire in great detail in gastritis cases, in low-grade ENMZL, transformed ENMZL and primary diffuse large B cell lymphoma (DLBL) and reported according to their own words unexpected results: (1) The repertoire is the same in gastritis with and without Helicobacter pylori (HP); this, however, makes sense as the response to HP is a $\mathrm{T}$ cell response and the $\mathrm{B}$ cell repertoire is not expected to be different. (2) The clone in ENMZL has a

J. H. van Krieken $(\bowtie)$

Department of Pathology, Radboud University Nijmegen Medical Centre, P.O. box 9101, 6500 HB Nijmegen, The Netherlands

e-mail: J.vankrieken@pathol.umcn.nl high diversity and mutational history, which again makes sense as ENMZL lymphoma is driven by processes that makes the cells resistant to apoptosis, so they can accumulate diversity. (3) De novo DLBL has limited diversity, which makes sense since these lymphomas are generally not seen as related to an immune response but to a mistake in the Ig-gene rearrangement process. Therefore, I think the data actually fit very well with our concept on the development of ENMZL.

Oricchio et al. [2] performed large-scale genomic analyses on follicular lymphomas (FL) with a detailed bioinformatics approach and found in $50 \%$ of the cases a genetic lesion that impairs the retinoblastoma $(\mathrm{Rb})$ pathway. These alterations include homozygous and heterozygous deletions of the p16/ CDKN2a/b (7 \%) and RB1 (12\%) loci, and more frequent gains of chromosome 12 that include CDK4 (29\%). These findings may indicate that a treatment approach that restores this pathway might be interesting.

Green et al. [3] found that gain of 3q27.2 (where Bc16 is located) is related to DLBL of the activated $B$ cell $(\mathrm{ABC})$ subtype but without overexpression of Bcl6. He also found that some hematopoietic stem cells express Bcl6 and that transient expression of Bcl6 can be induced in mouse hematopoietic stem cells. Since this resulted in the development of mature B cell lymphomas, they suggest that Bcl6 may have a "hit-and-run" role in lymphomagenesis.

FOXO1, which is highly expressed in B cells, is downregulated in classical Hodgkin lymphoma (cHL). Xie et al. [4] showed that also 19 out of 20 primary mediastinal B cell lymphomas (PMBL) lack or had low expression of FOXO1 and that this was inversely related to JAK2 expression. Targeting JAK2 in cell lines of this lymphoma type resulted in upregulation of FOXO1 mRNA and FOXO1 activation led to growth arrest and apoptosis. They conclude that FOXO1 repression might contribute to the oncogenic program and phenotype of PMBL, and of course therefore could be a target for therapy. 
Burkitt lymphoma (BL) is characterized by MYC deregulation resulting in high proliferation. According to experiments on cell lines, Schneider at al. [5] demonstrated that MYC deregulation results in miR-28 downregulation and that re-expression abrogates the effects of MYC. These data suggest that miR-28 acts as a tumor suppressor in $\mathrm{BL}$ and that its repression by MYC contributes to $\mathrm{B}$ cell lymphomagenesis.

\section{Epidemiology of lymphoma}

A very different approach toward lymphomagenesis comes from epidemiological studies. Nowadays, a large body of data is available on germline genetics and tumor genetics, and it is a big challenge how to get meaningful information out of that. Cozen et al. [6] analyzed publicly available data from 1,816 Hodgkin lymphoma (HL) patients and 7,877 controls and confirmed their results in another 1,281 and 3,218 cases, respectively. They identified a novel gene variant at 19p13.3 associated with HL, located in intron 2 of TCF3 (also known as E2A), a regulator of $\mathrm{B}$ and $\mathrm{T}$ cell lineage commitment known to be involved in HL pathogenesis. This meta-analysis also noted associations between previously published loci at 2p16, 5q31, 6p31, 8q24, and 10p14 and HL subtypes. They conclude that their data suggest a link between the 19p13.3 locus, including TCF3, and HL risk. A next step would require the development of a model in which such data lead to better understanding of the processes involved, but that remains a daunting task. Such a model would certainly include the Epstein-Barr virus (EBV) a well-known factor in a subset of HL cases. According to Lee et al. [7], who combined data from 119 published studies (including 13,045 cases), almost $50 \%$ of HL lymphomas cases carry EBV. They also showed that EBV positivity is more often found in children, mixed cellularity types and advanced stages, but that there is no prognostic impact. Very strong data indeed, but actually already well-known and accepted results.

Another piece of the model that explains the development of HL comes from Satoh et al. [8] who examined the tumor microenvironment in HL tissue samples and the expression of molecules related to EBV infection. They found in EBV-positive samples an increased population of FOXP3 $(+)$ cells, while that of granzyme $\mathrm{B}(+)$ cells was reduced, compared with those in EBV-negative HL. Furthermore, they found that the expression of the inhibitory chemokine CCL20 was increased in EBV-positive cells. How this piece of data has to be placed in the model remains unclear.

\section{Defining entities}

\section{Hodgkin lymphoma}

Most pathologist use EBV expression in the neoplastic cells as an argument against a diagnosis nodular lymphocytepredominant HL (NLPHL). According to Wang et al. [9], this is probably not completely correct. They reported on eight cases of EBV-positive NLPHL occurring in patients in the USA. These patients had no history of immunosuppression and presented with localized or systemic lymphadenopathy. Six cases had a vaguely nodular pattern and two cases had a nodular and diffuse pattern. The diagnosis was based on the typical phenotype, although CD30 was expressed variably in seven cases, while CD15 was invariable negative. They conclude that EBV infection is a rare event in NLPHL, which correlates with poorer prognosis. These data reinforce the notion that in lymphoma diagnosis and classification, there are few absolute markers and that a diagnosis remains one of combining information.

Hartmann et al. [10] investigated the same disease for pathological features that may predict prognosis. CD15, IgD, phosphorylated STAT6, ICOS, and Epstein-Barr virus status (they had also a few cases!) of the malignant lymphocytepredominant cells as well as epithelioid cell clusters and activated $\mathrm{T}$ cells in the microenvironment were not associated with a particular clinical outcome. They conclude their abstract by stating that patients presenting with epithelioid cell clusters showed a non-significant trend toward a lower relapse rate, justifying further evaluation of this marker. I would argue, that in such studies, a trend is not really worthwhile to pursue, unless there is a good hypothesis. It is highly likely that such a trend in such types of statistical analyses is really due to chance as the $p$ value already suggests.

About $30 \%$ of the NLPHL develop into DLBL. In another study by Hartmann et al. [11], 33 of such cases were investigated and compared with the results of 41 de novo DLBL. The immunophenotype of the DLBL secondary to NLPHL was heterogeneous, but BCL6, EMA, CD75, and J-chain were usually positive. In the independent series of de novo DLBL, 4 cases could be identified with a growth pattern and immunophenotype that suggested that they had arisen secondarily from NLPHL. It would be interesting to know whether these cases had a different clinical behavior.

\section{B cell lymphomas}

The diagnosis of nodal marginal zone lymphoma (NMZL) can be difficult. Metcalf et al. [12] investigated the expression of myeloid cell nuclear differentiation antigen (MNDA), a nuclear protein that labels myelomonocytic cells as well as B lymphocytes that localize to the marginal zone areas of splenic white pulp. A total of 440 tissue sections containing B cell 
lymphomas were stained for MNDA by immunohistochemistry: $67 \%$ of nodal MZL, $61 \%$ of extranodal MZL, and $24 \%$ of splenic MZL expressed MNDA; MNDA was infrequently expressed in other B cell neoplasms including mantle cell lymphoma (6\%), chronic lymphocytic leukemia/small lymphocytic lymphoma (13\%), FL (4\%), lymphoplasmacytic lymphoma (25\%), and DLBL (3\%). These data support the inclusion of MNDA in the diagnostic evaluation of $\mathrm{B}$ cell lymphomas, particularly those in which the differential diagnosis is between low-grade FL and MZL. These data are similar to those previously reported (reviewed by van den Brand et al. [13]).

The most recent WHO classification includes the still relatively poorly characterized category of the DLBL unclassifiable, with features in between HL and DLBL. These cases present commonly in the mediastinum and Wilson et al. [14] described 24 of such cases (a pity that they did not include cases outside the mediastinum): the patients had a median age of 33 (range 14-59) years and $46 \%$ had mediastinal masses $\geq 10 \mathrm{~cm}$. Five-year survival was about $75 \%$. The absolute lymphocyte count, the presence of tumor infiltrating dendritic cells, CD15 expression on the malignant cells, and tumor morphology were markers of outcome.

The diagnosis of primary mediastinal DLBL (PMDLBL) is mainly based on site of development. Although there are some typical morphological and phenotypical features for these lymphomas, it is virtually impossible to distinguish them from ordinary DLBL in the mediastinum. Amplification and/or translocations involving chromosome 9p24.1, a region that includes PDCD1LG2-encoding PD-L2, is a common event in PMDLBL but not DLBL. Therefore, Shi et al. [15] stained 32 PMDLBL and 37 DLBL for programmed cell death 1 ligand 2 (PD-L2), a cell surface protein expressed by activated macrophages and dendritic cells, which binds PD-1 on T cells. Twenty-three (72\%) PMBLs but only 1 (3\%) DLBL were positive, and this may serve as a useful ancillary test for distinguishing PMDLBL from DLBL and for the selection of patients for therapeutic antibodies that inhibit PD-1 signaling.

Plasmablastic lymphoma (PBL) is also a relatively poorly characterized entity and the term is somewhat ambiguous. Morscio et al. [16] described the clinicopathologic characteristics of 25 PBLs ( 2 in acquired immunodeficiency syndrome patients, 11 in immunocompetent individuals, 12 in transplant recipients) and of 277 PBLs from the literature. PBL patients were predominantly male $(77 \%)$ with a median age at diagnosis of 46 years (range 1.2 to 87 years). In the literature, only $66 \%$ of the biopsies was EBV positive, indicating a problem with definition, since some groups would require EBV for the diagnosis. Extranodal presentation was most frequent ( $88 \%$; of which $35 \%$ was oral, $18 \%$ was gastrointestinal, $12 \%$ was cutaneous). PBL was diagnosed in acquired immunodeficiency syndrome patients (50\%), immunocompetent individuals
(35\%), and transplant recipients (14\%). These subgroups differed in age at diagnosis (median 41, 64, 47 years, respectively), primary localization (oral, oral, cutaneous, respectively), EBV positivity (75, 50, $67 \%$, respectively), and C-MYC aberrations (78, 44, $38 \%$, respectively). Ann Arbor stage I, EBV positivity, and lack of C-MYC aberrations were associated with better outcome. The authors conclude that the results of this retrospective study suggest different pathogenic mechanisms of PBL in different immunologic settings and a potentially important impact of EBV; my interpretation would be that we use the term PBL not consistently and that it remains important to diagnose and classify in a clinical setting.

\section{T cell lymphomas}

Anaplastic lymphoma kinase (ALK)-positive anaplastic large cell lymphoma (ALCL) is now a well-defined disease category, but this is not the case for ALK-negative ALCL. Parilla Castellar et al. [17] collected 73 such cases and compared them with 32 ALK-positive cases. They identified chromosomal rearrangements of DUSP 22 and TP63 in 30 and $8 \%$ of ALK-negative ALCLs, respectively. These rearrangements were mutually exclusive and were absent in ALK-positive ALCLs. Five-year overall survival rates were $85 \%$ for ALK-positive ALCLs, $90 \%$ for DUSP22-rearranged ALCLs, $17 \%$ for TP63-rearranged ALCLs, and $42 \%$ for cases lacking all three genetic markers. They conclude that ALK-negative ALCL is a genetically heterogeneous disease with variable outcomes following standard therapy.

\section{Cutaneous lymphomas}

Patients who use methotrexate may develop lymphoproliferations that mimic lymphoma, especially HL, but upon withdrawal of the drug, the lesions most often regress. Koens et al. [18] described 10 cases, $5 \mathrm{EBV}(+)$ and 5 EBV $(-)$. Six patients had skin-limited disease. Clinically, abrogation of MTX therapy resulted in a complete response in 4 cases and a partial response in another 2; the 5-year diseasespecific survival was $90 \%$. Although these lesions differ clinically and morphologically from common B cell lymphomas of the skin, lack of knowledge on the use of methotrexate may result in a wrong diagnosis and unnecessary aggressive treatment.

Intravascular lymphomas follow an aggressive clinical course, but there are surprisingly indolent examples. Samols et al. [19] described 12 intralymphatic large T cell lymphomas; 9 were CD30 positive, 5 of which were ALK positive. The clinical and pathologic characteristics of the CD30 T cell lymphoproliferative disorders (T-LPDs) were similar to those of their extravascular counterparts, including a better outcome compared to intravascular DLBL. 


\section{New entities/subtypes}

Van der Velden et al. [20] evaluated seven B cell prolymphocytic leukemia (B-PLL) cases with a $t(11 ; 14)$ (BPLL+), now referred to as mantle cell lymphoma (MCL) and compared them with six without the translocation (B-PLL-). EuroFlow-based immunophenotyping showed significant overlap between B-PLL + and B-PLL-, as well as between B-PLL and MCL, whereas CLL clustered separately. Immunogenotyping of translocation positive cases showed specific IGHV gene usage partly resembling MCL. Gene expression profiling showed no separation between B-PLL+ and B-PLL- but identified three subgroups. One B-PLL subgroup clustered close to CLL and another subgroup clustered with leukemic MCL; both were associated with prolonged survival. A third subgroup clustered close to nodal MCL and was associated with short survival. The data indicate that BPLL with $t(11 ; 14)$ is highly comparable to MCL. The authors propose that also B-PLL without $t(11 ; 14)$ may be considered as a subgroup of MCL and that B-PLL is part of a spectrum, ranging from CLL-like B-PLL, to leukemic MCL-like B-PLL, to nodal MCL-like B-PLL. This conclusion is at odds with the way we now classify lymphomas, namely grouping them into disease entities. Since the data were derived from blood samples only, it is difficult to put them in the context of tissuebased classified cases.

EBV has a role in several different lymphoma entities, but one of the most enigmatic is EBV-positive DLBL of the elderly. It has been assumed that this is probably related to an unknown immune defect that is the result of aging, but no solid data are available for that. Cohen et al. [21] found in a series of 75 DLBL in 7 cases (9\%) the presence of EBV-encoded RNAs (EBERs), which was $13 \%$ in patients older than 50 and $8 \%$ in those who were younger. These cases had no different $\mathrm{T}$ cell infiltrate and a variable latency pattern. In a previous review, I mentioned that the cut-off for age is indeed arbitrary, and at this point, we lack good understanding of the underlying mechanisms.

As mentioned above, the role of HP in gastric low-grade ENMZL is well established. Kuo et al. [22] collected a series of 46 primary DLBL of the stomach in which there was HP gastritis and compared them with 49 that were HP negative. HP-positive patients had a lower International Prognostic Index score, a lower clinical stage, a better tumor response to chemotherapy, and a significantly better overall survival. The authors conclude that HP-related gastric DLBCL may be a distinct tumor entity, which is less aggressive, and responds better to conventional chemotherapy. An alternative explanation could be that patients with HP gastritis and DLBL have more complaints than those who do not have gastritis and may seek medical care earlier in the disease process.

\section{Pitfalls in lymphoma diagnosis}

In some cases, the distinction between a reactive immunoblastic proliferation and HL is difficult and loss of expression of B cell antigens is used as a marker for HL. Treetipsatit et al. [23] investigated 33 cases of reactive immunoblastic proliferations to see how well the B cell program, as determined by immunohistochemistry, was preserved. The majority of immunoblasts expressed CD30 in 14 of 33 (42\%) cases; none expressed CD15. Loss or weak expression of at least one transcription factor in B immunoblasts, most commonly PAX5, was noted in 24 of 29 (83\%) cases. A polytypic light chain expression pattern was detected by immunohistochemistry in 14 of $22(63.6 \%)$ cases and by dual-color chromogenic in situ hybridization in 9 of $10(90 \%)$ cases studied. EBV was present in 8 of 33 (24.2\%) cases. Because B cell transcription factors can show loss or weak expression in a significant proportion of reactive immunoblastic proliferations, care has to be taken to avoid misdiagnosis of HL in such cases. It remains very important to realize that indeed HL is not a diagnosis based on immunohistochemistry only and that the morphology of the correct neoplastic cells in a specific inflammatory environment remains a cornerstone of the diagnosis.

\section{Staging}

Evaluating bone marrow biopsies for staging of lymphoma patients is commonly not difficult, especially with the use of immunohistochemistry. A notable exception is angioimmunoblastic T cell lymphoma (AILT), in which the amount of neoplastic cells may be low. Cogbill et al. [24] stained bone marrow biopsies with CD279/PD1 and found scattered positive cells not only in 7/10 staging biopsies of AILT patients but also in biopsies for staging of patients with other types of $\mathrm{T}$ cell lymphomas, and even in some benign lesions, there were such cells. They conclude that CD279 immunohistochemistry is a helpful tool for staging AILT patients but that it is not specific enough to make a diagnosis of AILT on the immunostain alone.

\section{Ancillary techniques}

Although nowadays much attention is given to molecular, DNA and RNA based, methods, there is also increasing relevance for methods to identify and quantify proteins in tissue sections. We routinely use immunohistochemistry for diagnostic purposes and increasingly for prediction of therapy effect. The interest to have data on multiple proteins in one cell is high but double or multiple stainings are rarely used in a routine practice. Hollman-Hewgley et al. [25] describe their experience with a single-slide multiplex assay based on 
fluorescence in the evaluation of HL. The method, MultiOmyx ${ }^{\mathrm{TM}}$, may be applied to stain with more than 60 antibodies on single-tissue sections from formalin-fixed paraffin-embedded tissue. They developed the assay for CD30, CD15, PAX-5, CD20, CD79a, CD45, BOB.1, OCT-2, and CD3 multiplexing and describe a high degree of sensitivity, specificity, and precision. There was complete concordance of the diagnosis in 54 of 56 cases with routine staining. The 2 discordant cases illustrated the potential of this multiplexed immunofluorescence technology to improve on traditional immunohistochemistry. A totally different approach was chosen by van den Brand et al. [26] who used sequential immunohistochemistry with digital scanning in between, by which also expression of different proteins on a single cells is visualized, but now with bright field microscopy. Schlederer et al. [27] used an image analysis approach to quantify protein as detected by immunohistochemistry in mouse models where the levels of protein were standardized. Image analysis was able to accurately detect allelic loss at the protein level and nuclear signals were distinguished from cytoplasmic expression and translocation of transcription factors from the cytoplasm to the nucleus was reliably detected and quantified. Although these methods are presently mainly used for scientific purposes, they might become relevant when more predictive markers are introduced in routine practice.

\section{References}

1. Michaeli M, Tabibian-Keissar H, Schiby G, Shahaf G, Pickman Y, Hazanov L, Rosenblatt K, Dunn-Walters DK, Barshack I, Mehr R (2014) Immunoglobulin gene repertoire diversification and selection in the stomach-from gastritis to gastric lymphomas. Front Immunol 5:264, eCollection 2014

2. Oricchio E, Ciriello G, Jiang M, Boice MH, Schatz JH, Heguy A, Viale A, de Stanchina E, Teruya-Feldstein J, Bouska A, McKeithan T, Sander C, Tam W, Seshan VE, Chan WC, Chaganti RS, Wendel HG (2014) Frequent disruption of the RB pathway in indolent follicular lymphoma suggests a new combination therapy. J Exp Med 211:1379-1391

3. Green MR, Vicente-Dueñas C, Romero-Camarero I, Long Liu C, Dai B, González-Herrero I, García-Ramírez I, Alonso-Escudero E, Iqbal J, Chan WC, Campos-Sanchez E, Orfao A, Pintado B, Flores T, Blanco O, Jiménez R, Martínez-Climent JA, Criado FJ, Cenador MB, Zhao S, Natkunam Y, Lossos IS, Majeti R, Melnick A, Cobaleda C, Alizadeh AA, Sánchez-García I (2014) Transient expression of Bcl6 is sufficient for oncogenic function and induction of mature B-cell lymphoma. Nat Commun 5:3904

4. Xie L, Ritz O, Leithäuser F, Guan H, Färbinger J, Weitzer CD, Gehringer F, Bruederlein S, Holzmann K, Vogel MJ, Möller P, Wirth T, Ushmorov A (2014) FOXO1 downregulation contributes to the oncogenic program of primary mediastinal B-cell lymphoma. Oncotarget 5:5392-5402

5. Schneider C, Setty M, Holmes AB, Maute RL, Leslie CS, Mussolin L, Rosolen A, Dalla-Favera R, Basso K (2014) MicroRNA 28 controls cell proliferation and is down-regulated in B-cell lymphomas. Proc Natl Acad Sci U S A 111:8185-8190
6. Cozen W, Timofeeva MN, Li D, Diepstra A, Hazelett D, DelahayeSourdeix M, Edlund CK, Franke L, Rostgaard K, Van Den Berg DJ, Cortessis VK, Smedby KE, Glaser SL, Westra HJ, Robison LL, Mack TM, Ghesquieres H, Hwang AE, Nieters A, de Sanjose S, Lightfoot T, Becker N, Maynadie M, Foretova L, Roman E, Benavente Y, Rand KA, Nathwani BN, Glimelius B, Staines A, Boffetta P, Link BK, Kiemeney L, Ansell SM, Bhatia S, Strong LC, Galan P, Vatten L, Habermann TM, Duell EJ, Lake A, Veenstra RN, Visser L, Liu Y, Urayama KY, Montgomery D, Gaborieau V, Weiss LM, Byrnes G, Lathrop M, Cocco P, Best T, Skol AD, Adami HO, Melbye M, Cerhan JR, Gallagher A, Taylor GM, Slager SL, Brennan P, Coetzee GA, Conti DV, Onel K, Jarrett RF, Hjalgrim H, Van Den Berg A, McKay JD (2014) A meta-analysis of Hodgkin lymphoma reveals 19p13.3 TCF3 as a novel susceptibility locus. Nat Commun 5:3856

7. Lee JH, Kim Y, Choi JW, Kim YS (2014) Prevalence and prognostic significance of Epstein-Barr virus infection in classical Hodgkin's lymphoma: a meta-analysis. Arch Med Res 45:417-431

8. Satoh T, Wada R, Yajima N, Imaizumi T, Yagihashi S (2014) Tumor microenvironment and RIG-I signaling molecules in Epstein Barr virus-positive and -negative classical Hodgkin lymphoma of the elderly. J Clin Exp Hematop 54:75-84

9. Wang S, Medeiros LJ, Xu-Monette ZY, Zhang S, O'Malley DP, Orazi A, Zuo Z, Bueso-Ramos CE, Yin CC, Liu Z, Miranda RN, Young KH (2014) Epstein-Barr virus-positive nodular lymphocyte predominant Hodgkin lymphoma. Ann Diagn Pathol 18(4):203-209

10. Hartmann S, Eichenauer DA, Plütschow A, Mottok A, Bob R, Koch K, Bernd HW, Cogliatti S, Hummel M, Feller AC, Ott G, Möller P, Rosenwald A, Stein H, Hansmann ML, Engert A, Klapper W (2014) Histopathological features and their prognostic impact in nodular lymphocyte-predominant Hodgkin lymphoma - a matched pair analysis from the German Hodgkin Study Group (GHSG). Br J Haematol. doi:10.1111/bjh.12997

11. Hartmann S, Eray M, Döring C, Lehtinen T, Brunnberg U, Kujala P, Vornanen M, Hansmann ML (2014) Diffuse large B cell lymphoma derived from nodular lymphocyte predominant Hodgkin lymphoma presents with variable histopathology. BMC Cancer 14:332

12. Metcalf RA, Monabati A, Vyas M, Roncador G, Gualco G, Bacchi CE, Younes SF, Natkunam Y, Freud AG (2014) Myeloid cell nuclear differentiation antigen is expressed in a subset of marginal zone lymphomas and is useful in the differential diagnosis with follicular lymphoma. Hum Pathol 45:1730-1736

13. van den Brand M, van Krieken JH (2013) Recognizing nodal marginal zone lymphoma: recent advances and pitfalls. A systematic review. Haematologica 98:1003-1013

14. Wilson WH, Pittaluga S, Nicolae A, Camphausen K, Shovlin M, Steinberg SM, Roschewski M, Staudt LM, Jaffe ES, Dunleavy K (2014) A prospective study of mediastinal gray zone lymphoma. Blood. doi:10.1182/blood-2014-03-564906

15. Shi M, Roemer MG, Chapuy B, Liao X, Sun H, Pinkus GS, Shipp MA, Freeman GJ, Rodig SJ (2014) Expression of programmed cell death 1 ligand 2 (PD-L2) is a distinguishing feature of primary mediastinal (thymic) large B-cell lymphoma and associated with PDCD1LG2 Copy Gain. Am J Surg Pathol. doi:10.1097/PAS. 0000000000000297

16. Morscio J, Dierickx D, Nijs J, Verhoef G, Bittoun E, Vanoeteren X, Wlodarska I, Sagaert X, Tousseyn T (2014) Clinicopathologic comparison of plasmablastic lymphoma in HIV-positive, immunocompetent, and posttransplant patients: single-center series of 25 cases and meta-analysis of 277 reported cases. Am J Surg Pathol 38:875-886

17. Parilla Castellar ER, Jaffe ES, Said JW, Swerdlow SH, Ketterling RP, Knudson RA, Sidhu JS, Hsi ED, Karikehalli S, Jiang L, Vasmatzis G, Gibson SE, Ondrejka S, Nicolae A, Grogg KL, Allmer C, Ristow KM, Wilson WH, Macon WR, Law ME, Cerhan JR, Habermann TM, Ansell SM, Dogan A, Maurer MJ (2014) Feldman ALALKnegative anaplastic large cell lymphoma is a genetically 
heterogeneous disease with widely disparate clinical outcomes. Blood. doi:10.1182/blood-2014-04-571091

18. Koens L, Senff NJ, Vermeer MH, Willemze R, Jansen PM (2014) Methotrexate-associated B-cell lymphoproliferative disorders presenting in the skin: a clinicopathologic and immunophenotypical study of 10 cases. Am J Surg Pathol 38:999-1006

19. Samols MA, Su A, Ra S, Cappel MA, Louissant A Jr, Knudson RA, Ketterling RP, Said J, Binder S, Harris NL, Feldman AL, Kim J, Kim YH, Gratzinger D (2014) Intralymphatic cutaneous anaplastic large cell lymphoma/lymphomatoid papulosis: expanding the spectrum of CD30-positive lymphoproliferative disorders. Am J Surg Pathol 38: 1203-1211

20. van der Velden VH, Hoogeveen PG, De Ridder D, Schindler-van Der Struijk M, van Zelm MC, Sanders M, Karsch D, Beverloo HB, Lam K, Orfao A, Lugtenburg PJ, Böttcher S, van Dongen JJ, Langerak AW, Kappers-Klunne M, van Lom K (2014) B-cell prolymphocytic leukemia: a specific subgroup of mantle cell lymphoma. Blood 124:412-9

21. Cohen M, Narbaitz M, Metrebian F, De Matteo E, Preciado MV, Chabay PA (2014) Epstein-Barr virus-positive diffuse large B-cell lymphoma association is not only restricted to elderly patients. Int $\mathbf{J}$ Cancer. doi:10.1002/ijc. 28942

22. Kuo SH, Yeh KH, Chen LT, Lin CW, Hsu PN, Hsu C, Wu MS, Tzeng YS, Tsai HJ, Wang HP, Cheng AL (2014) Helicobacter pylori-related diffuse large B-cell lymphoma of the stomach: a distinct entity with lower aggressiveness and higher chemosensitivity. Blood Cancer J 4: e220

23. Treetipsatit J, Rimzsa L, Grogan T, Warnke RA, Natkunam Y (2014) Variable expression of B-cell transcription factors in reactive immunoblastic proliferations: a potential mimic of classical Hodgkin lymphoma. Am J Surg Pathol. doi:10.1097/PAS. 0000000000000266

24. Cogbill CH, Swerdlow SH, Gibson SE (2014) Utility of CD279/PD1 immunohistochemistry in the evaluation of benign and neoplastic T-cell-rich bone marrow infiltrates. Am J Clin Pathol 142:88-98

25. Hollman-Hewgley D, Lazare M, Bordwell A, Zebadua E, Tripathi P, Ross AS, Fisher D, Adams A, Bouman D, O'Malley DP, Weiss LM (2014) A single slide multiplex assay for the evaluation of classical Hodgkin lymphoma. Am J Surg Pathol 38:1193-1202

26. van den Brand M, Hoevenaars BM, Sigmans JH, Meijer JW, van Cleef PH, Groenen PJ, Hebeda KM, van Krieken JH (2014) Sequential immunohistochemistry: a promising new tool for the pathology laboratory. Histopathology. doi:10.1111/his.12446

27. Schlederer M, Mueller KM, Haybaeck J, Heider S, Huttary N, Rosner M, Hengstschläger M, Moriggl R, Dolznig H, Kenner L (2014) Reliable quantification of protein expression and cellular localization in histological sections. PLoS ONE 9:e100822 